\title{
BI-BAND Bow-TIE ANTENNAS ARray DEsign USING A SIMPLE EQUIVALENT TRANSMISSION LINE MODEL
}

\author{
M. Abri $^{1}$, H. Abri Badaoui ${ }^{2}$, H. Dib ${ }^{1}$ and A. S. E. Gharnaout ${ }^{1}$ \\ ${ }^{1}$ Laboratoire de Télécommunications, Département de Génie Electrique \\ Faculté de Technologie, Université Abou-Bekr Belkaïd -Tlemcen \\ BP 230, Pôle Chetouane, 13000 Tlemcen- Algérie \\ abrim2002@yahoo.fr, salimttleyahoo.fr \\ ${ }^{2}$ Laboratoire STIC, Département de Génie Electrique \\ Faculté de Technologie, Université Abou-Bekr Belkaïd -Tlemcen \\ BP 230, Pôle Chetouane, 13000 Tlemcen- Algérie \\ elnbheyahoo.fr
}

\begin{abstract}
In this paper we propose a simple equivalent and accurate transmission line model for bi-band bow-tie antennas array design over a band of frequencies for satellite communications. This model uses the resistance of a square element that appears at the edges of the antenna (radiating slots). To test this model, two antennas array were simulated and results were compared with those obtained by a rigorous method (moment's method) of the simulator ADS/Momentum. Using this transmission line approach the resonant frequency, return loss, VSWR, reflected phase, input impedance can be determined simultaneously. The results confirm the validity of the proposed model.
\end{abstract}

\section{KEY WORDS}

Bi-band bow-tie antennas array, transmission line model, Momentum software.

\section{INTRODUCTION}

In recent years, several studies have been developed in the Telecommunications field. Transmission systems in space using printed antennas have many advantages. These systems meet the constraints of mobility, accessibility and the used frequency; they may have sufficient capacity without amplification. The choice of these antennas is based on application constraints such as frequency, gain, cost, coverage, weight ... etc.

Many researchers have studied their basic characteristics and major efforts were also devoted to determining the resonant frequency, bandwidth, radiation ... etc [1-4]. Although printed antennas appear simple and easy to manufacture, but to seek the electromagnetic properties that meet all the conditions is a complicated task. The bow-tie antennas are well known for their multiband abilities and advantageous characteristics. They are used in communication systems, and several structures have been recently proposed in literature [5-7].

The printed antennas characterization requires the use of software using rigorous numerical methods such as integral equations solved by the moment's method. These we offer precision, but they require tedious calculations. The transmission line model seems to be the best solution. 
International Journal of Computer Networks \& Communications (IJCNC) Vol.4, No.4, July 2012

In this paper we develop an equivalent model fast, simple and accurate to reflect all the geometrical, electrical and technological of bow-tie antennas and their feeds. A rigorous method which is the method of moments of momentum software was chosen to demonstrate the validity of the proposed model.

\section{Transmission Line Model Formulation}

\section{1. Methods used for printed antennas analysis}

Although they have simple geometries, the printed antennas are difficult to study because of their non-homogeneity of the environment that supports them. This results in complex boundary conditions, especially air-dielectric interface which makes it difficult to solve the Helmholtz equations.

Because of this difficulty, various approximate methods have been proposed [8-9] for printed antennas radio characteristics determination (resonant frequency, bandwidth, gain, input impedance, directivity...) based on the determination the current surface distribution. Among these methods we find the transmission line model.

\section{2. Transmission line model}

This technique treats the radiating element as a resonant line showing no change in the transverse field. The only variation in the field is along the length of the antenna [10-12].

\section{Radiating slots}

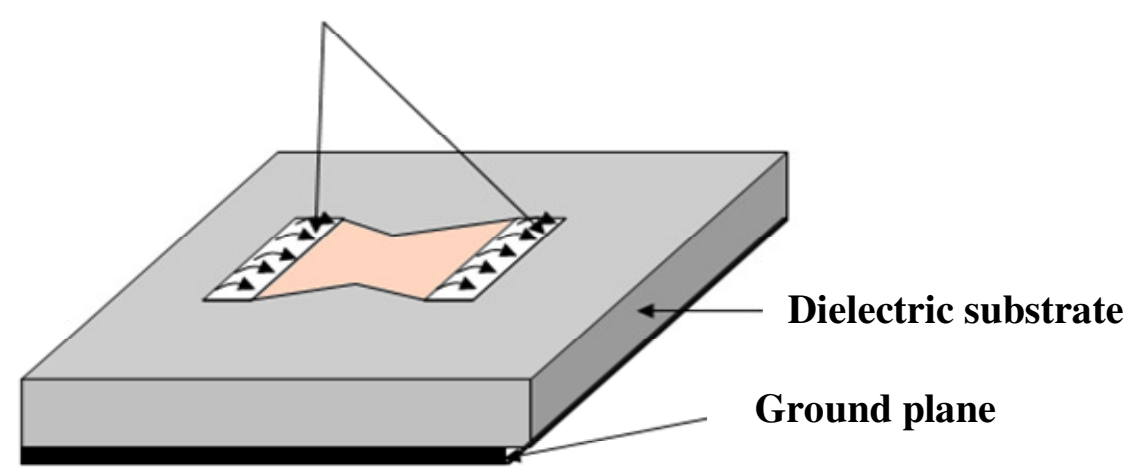

Figure 1. Transmission line model principle

The radiation from this antenna appears at its ends that are modelled by two radiating slots, separated by a transmission line the same length as the antenna (Figure. 1). It is a simple method that generates a good interpretation of radiation mechanism.

\section{SINGLE BOW-TIE ANTENNA FED BY A MICROSTRIP LINE}

The basic concept of the bow-tie antenna transmission line model fed by a microstrip line is presented in Figure 2. 
International Journal of Computer Networks \& Communications (IJCNC) Vol.4, No.4, July 2012

Because of edge effects, the microstrip antenna is greater than its physical dimensions. This is shown in Figure 2 (b) where the size of the antenna along its length was extended on each end by a distance $\Delta \mathrm{L}$, which is a function of dielectric constant and effective $\varepsilon_{\text {reff }}$ ratio of width $W_{l}$ on the thickness $h\left(W_{l} / h\right)$.

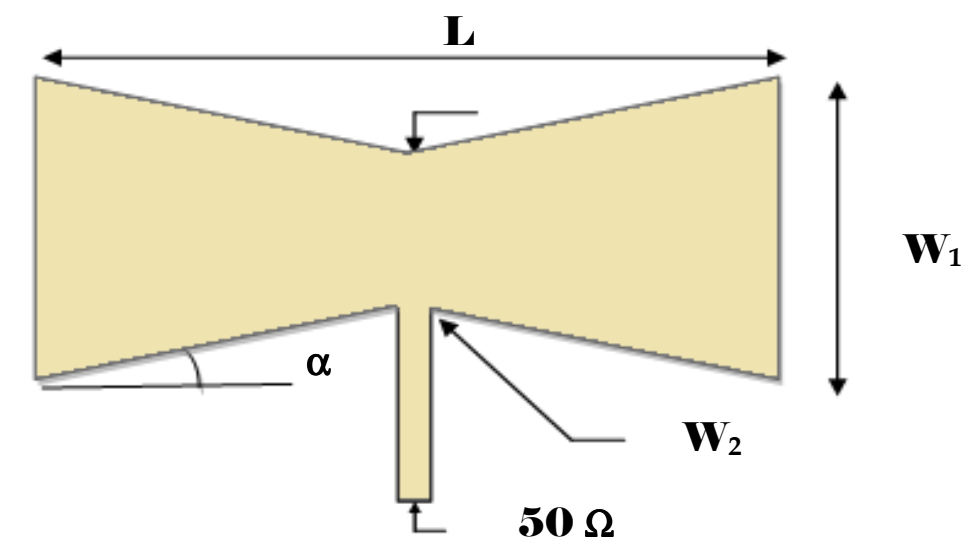

(a)

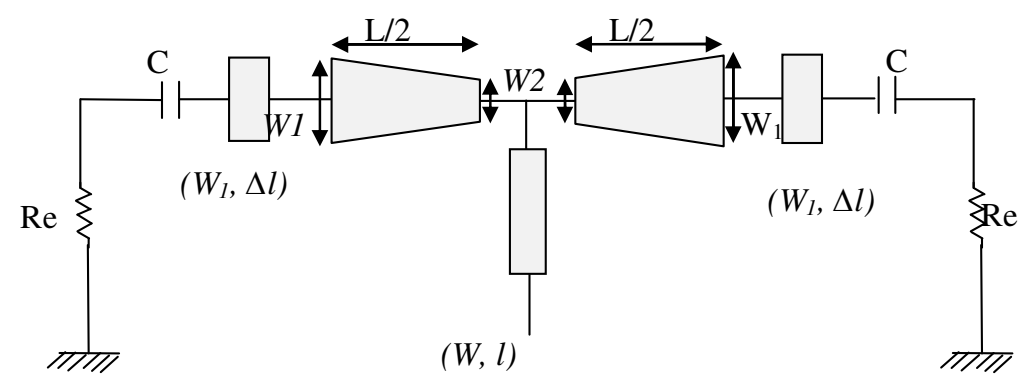

(b)

Figure 2. (a) Single bow-tie antenna fed by a microstrip line. (b) Equivalent model of the proposed antenna.

\section{TRANSMISSION LINE MODEL USED FOR ANTENNA ARRAYS}

In order to overcome the disadvantages of the single element (low gain, narrow band ..), the printed antennas are associated in arrays. There are two types of arrays: the linear array and planar array. Let us consider the linear array fed in series by microstrip line as it is presented in figure 3. To avoid the inter-element coupling, we set the value of the distance between the adjacent patches $\mathrm{d}=\frac{\lambda_{\mathrm{g}}}{2}$. 
International Journal of Computer Networks \& Communications (IJCNC) Vol.4, No.4, July 2012

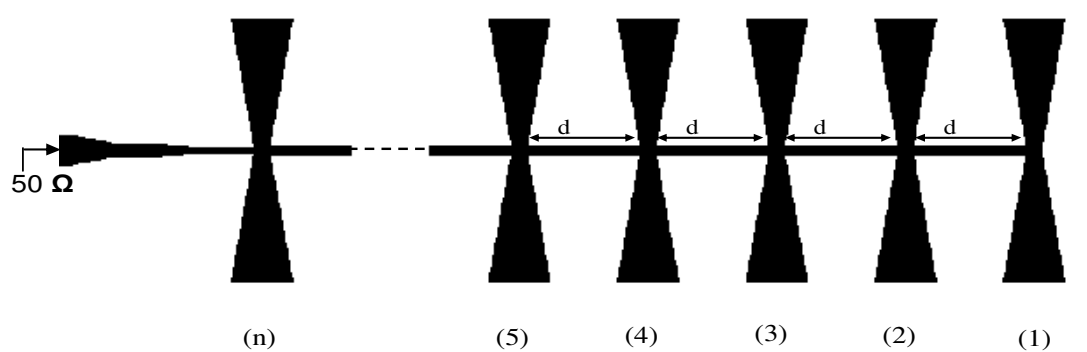

(a)

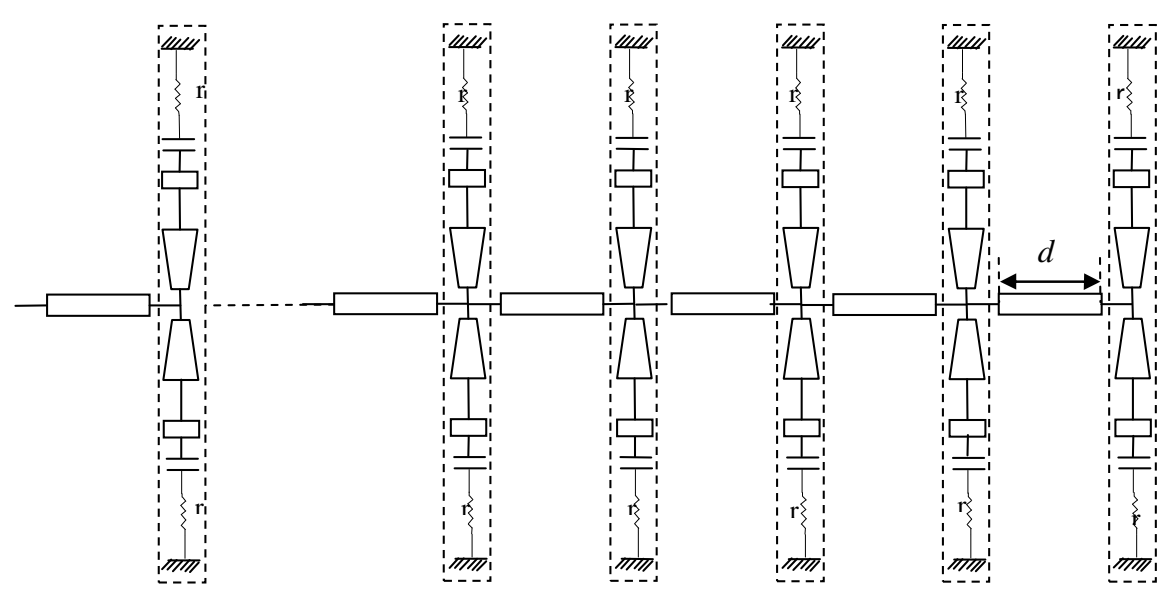

(b)

Figure 3. (a) Bow-tie antennas array geometry fed in series by a microstrip line. (b) equivalent model of the proposed antennas array.

An approximate relationship very popular and convenient for the extension of the normal length is given [13].

$$
\frac{\Delta \mathrm{L}}{\mathrm{h}}=0.412 \frac{\left(\varepsilon_{\text {reff }}+0.3\right)\left(\frac{\mathrm{W}_{1}}{\mathrm{~h}}+0.264\right)}{\left(\varepsilon_{\text {reff }}-0.258\right)\left(\frac{\mathrm{W}_{1}}{\mathrm{~h}}+0.8\right)}
$$

Since the length of the antenna was extended by $\Delta \mathrm{L}$ of each side, the length of the antenna is now:

$\mathrm{L}_{\mathrm{eff}}=\mathrm{L}+2 \Delta \mathrm{L}$

The resonant frequency of the printed antenna is a function of its length. It is given by equation (3) $[14]$. 


$$
\mathrm{f}_{\mathrm{r}}=\frac{1}{2 \mathrm{~L} \sqrt{\varepsilon_{\mathrm{r}}} \sqrt{\mu_{0} \varepsilon_{0}}}=\frac{\mathrm{v}_{0}}{2 \mathrm{~L} \sqrt{\varepsilon_{\mathrm{r}}}}
$$

Where:

- $\mu_{0}$ : Permeability of free space

- $\varepsilon_{0}$ : Permittivity of free space

- $\Delta \mathrm{L}$ : Line extension

- $\varepsilon_{\mathrm{eff}}$ : Effective dielectric constant

Since equation (3) does not include the length of the actual antenna, it is modified to include edge effects.

The effective width of the antenna is given by the following formula:

$$
\mathrm{W}_{1}=\frac{1}{2 \mathrm{f}_{\mathrm{r}} \sqrt{\mu_{0} \varepsilon_{0}}} \sqrt{\frac{2}{\varepsilon_{\mathrm{r}}+1}}=\frac{\mathrm{v}_{0}}{2 \mathrm{f}_{\mathrm{r}}} \sqrt{\frac{2}{\varepsilon_{\mathrm{r}}+1}}
$$

The actual length of the antenna can now be determined and is given by the following formula:

$$
\mathrm{L}=\frac{1}{2 \mathrm{f}_{\mathrm{r}} \sqrt{\varepsilon_{\text {reff }}} \sqrt{\mu_{0} \varepsilon_{0}}}-\Delta \mathrm{L}
$$

Each radiating slot is represented by an equivalent parallel admittance (Y) (with conductance $\mathrm{G}$ and susceptance B) [15].

$\mathrm{Y}=\mathrm{G}+\mathrm{jB}$

The expressions of $\mathrm{G}$ and $\mathrm{B}$ are given by the relations below:

$$
\left\{\begin{array}{l}
\mathrm{G}=\frac{\mathrm{W}}{120 \lambda_{0}}\left[1-\frac{1}{24}\left(\mathrm{k}_{0} \mathrm{~h}\right)^{2}\right] \text { for } \frac{\mathrm{h}}{\lambda_{0}}<\frac{1}{10} \\
\mathrm{~B}=\frac{\mathrm{W}}{120 \lambda_{0}}\left[1-0.636 \ln \left(\mathrm{k}_{0} \mathrm{~h}\right)\right] \text { for } \frac{\mathrm{h}}{\lambda_{0}}<\frac{1}{10}
\end{array}\right.
$$

The characteristic impedance is given by: 
International Journal of Computer Networks \& Communications (IJCNC) Vol.4, No.4, July 2012

$$
\mathrm{Z}_{\mathrm{c}}=\left\{\begin{array}{l}
\frac{120 \pi}{\sqrt{\varepsilon_{\text {reff }}}\left[\frac{\mathrm{W}}{\mathrm{h}}+1.393+0.667 \ln \left(\frac{\mathrm{W}}{\mathrm{h}}+1.444\right)\right]} \\
\text { pour } \left.\frac{\mathrm{W}}{\mathrm{h}}\right\rangle 1 \\
\frac{60}{\sqrt{\varepsilon_{\text {reff }}}} \ln \left[\frac{8 \mathrm{~h}}{\mathrm{~W}}+\frac{\mathrm{W}}{4 \mathrm{~h}}\right] \text { pour } \frac{\mathrm{W}}{\mathrm{h}} \leq 1
\end{array}\right.
$$

The input resistance is given by:

$R_{e}=\frac{1}{2\left(G+G_{12}\right)} \times\left[\cos ^{2}\left(\beta_{g} L\right)+\frac{G^{2}+B^{2}}{Y_{c}^{2}} \sin ^{2}\left(\beta_{g} L\right)-\frac{B}{Y_{c}} \sin \left(2 \beta_{g} L\right)\right]^{-1}$

$\mathrm{G}_{12}$ can be calculated.

$$
\mathrm{G}_{12}=\frac{1}{120 \pi^{2}} \int_{0}^{\pi}\left[\frac{\sin \left(\frac{\mathrm{k}_{0} \mathrm{w}}{2} \cos \theta\right)}{\cos \theta}\right]^{2} \mathrm{~J}_{0}\left(\mathrm{k}_{0} \mathrm{~L} \sin \theta\right) \sin ^{3} \theta \mathrm{d} \theta
$$

Where:

$\mathrm{J}_{0}$ is the Bessel function of first kind of order zero.

\section{RESULTS AND DISCUSSSION}

In this section, we present the bow-tie antenna simulation results. The validity of this model is highlighted by comparing the results of return loss, the VSWR, reflected phase and the input impedance locations with those obtained by the method of moments.

The antenna basic element is a conducting band of a bow-tie form deposited on a dielectric substrate of dielectric constant $\varepsilon r$ and thickness $h$ reinforced by a plane. In the design of our antenna, the design is one of the most important phases. The transmission line model is used to determine the dimensions of our antennas.

\subsection{Bi-band bow-tie antennas array operating at the frequencies 8.6 and $12.6 \mathrm{GHz}$}

The dimensions of the single bow-tie antenna are: $\mathrm{W}_{1}=8 \mathrm{~mm}, \mathrm{~W}_{2}=2 \mathrm{~mm}, \mathrm{~L}=34 \mathrm{~mm}$ and $\alpha=10^{\circ}$. The bow-tie antennas array is to be designed on a substrate witch has a relative permittivity $\varepsilon_{\mathrm{r}}$ of 4.6 , a dielectric thickness $\mathrm{h}$ of $0.444 \mathrm{~mm}$, a loss tangent of about 0,0018 and $0.05 \mathrm{~mm}$ conductor thickness. Using the transmission line model, the return loss, VSWR, reflected phase and input impedance locus are analysed in advance and its resonant frequencies are found to be in the band [6.0-14.0 GHz]. Because the input impedance of a patch at its edges is usually too high for direct connection to the feeding line, whose standard impedance is 50 $\mathrm{Ohm}$. A quarter wave transformer can be designed to achieve a satisfactory return loss at the resonant frequency.

The antennas array architecture is shown in the figure below. Note that the values are given in $\mathrm{mm}$. 


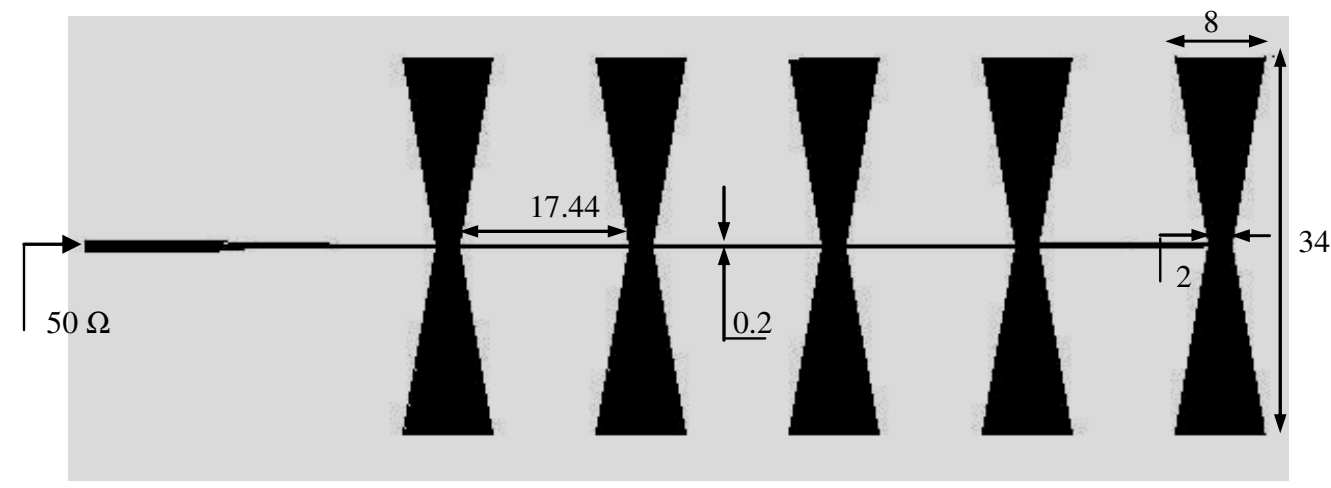

Figure 4. The mask layout of the bi-band bow-tie antennas array design operating at 8.6 and $12.6 \mathrm{GHz}$

The simulated input return loss of the antennas array is displayed for frequencies between 6.0 to 14.0 $\mathrm{GHz}$ in figure 5 .

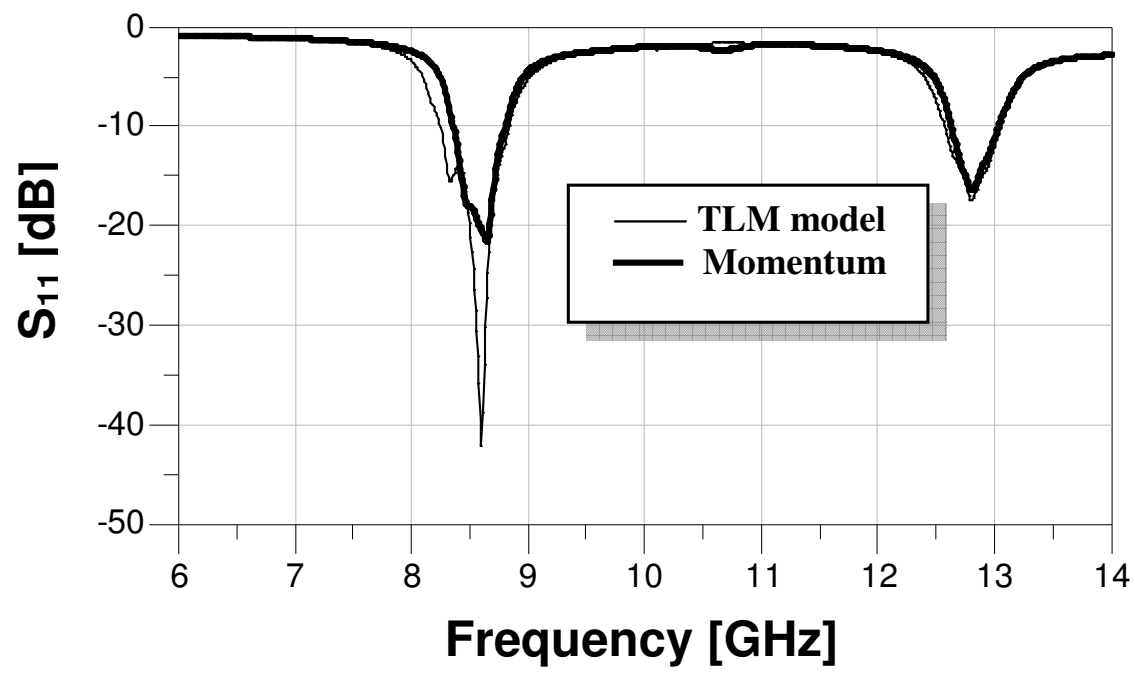

Figure 5. Computed return loss of the bi-band bow-tie antennas array

Let us notice that the two curves are almost identical. It is well observed that the resonance of the antennas array is correctly predicted to 8.6 and $12.6 \mathrm{GHz}$ with a light shift by the moment's method of the momentum software. A good adaptation is observed at the first frequency where the peak level recorded is approximately $-42.08 \mathrm{~dB}$ at the first frequency and of about $-17 \mathrm{~dB}$ at the second frequency by the transmission line model. The curve obtained by the method of moments has a peak level of about $-21.5 \mathrm{~dB}$ at the first frequency end of about $-17.2 \mathrm{~dB}$ at the second frequency.

The simulated VSWR is represented on figure 6. 
International Journal of Computer Networks \& Communications (IJCNC) Vol.4, No.4, July 2012

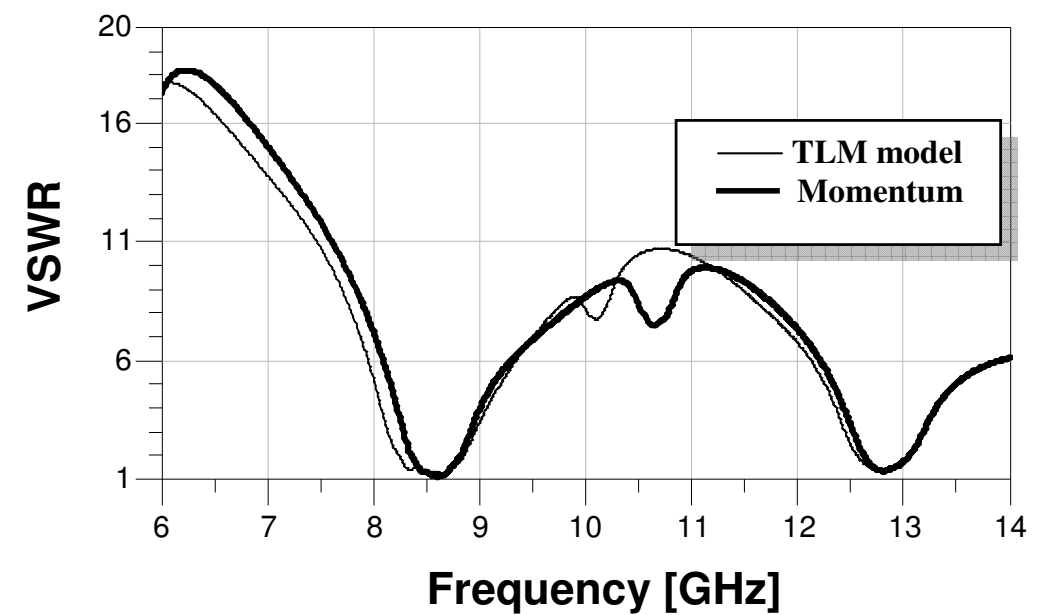

Figure 6. Simulated input VSWR of the bi-band bow-tie antennas array

According to the result shown in figure 6, we see excellent agreement between the two models (the transmission line model and the moment's method). The VSWR level at resonant frequency is near unity, which implies an ideal adaptation of the antenna.

The simulation result of the reflected phase at the input of the bi-band bow-tie antennas array is shown in figure 7 .

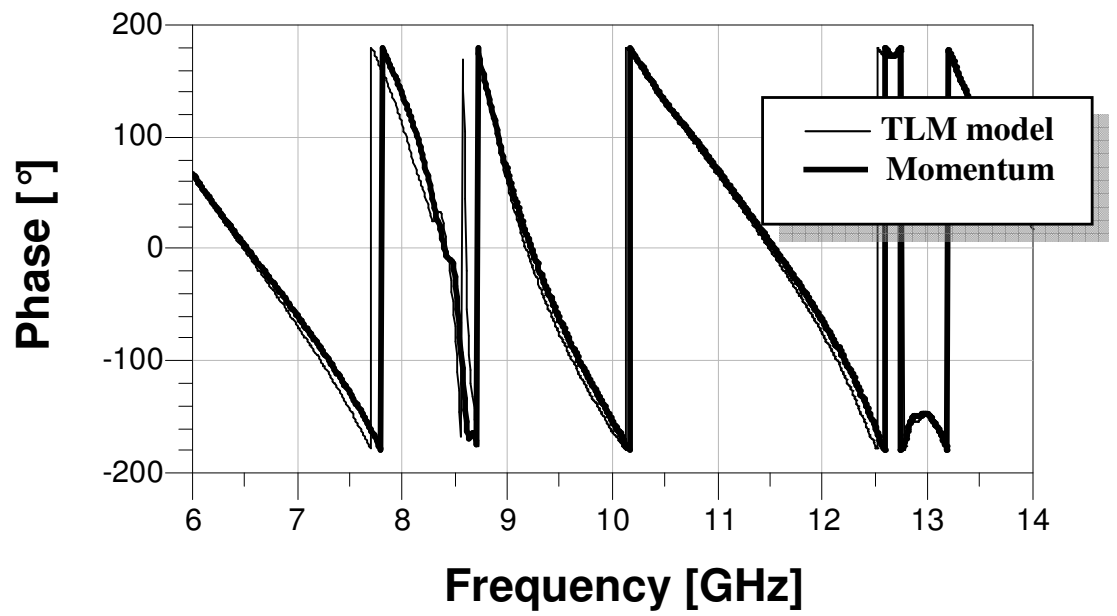

Figure 7. computed reflected phase of bi-band bow-tie antennas array

The impedance locus of the antennas array from 6.0 to $14.0 \mathrm{GHz}$ is illustrated on Smith's chart in figure 8 . 


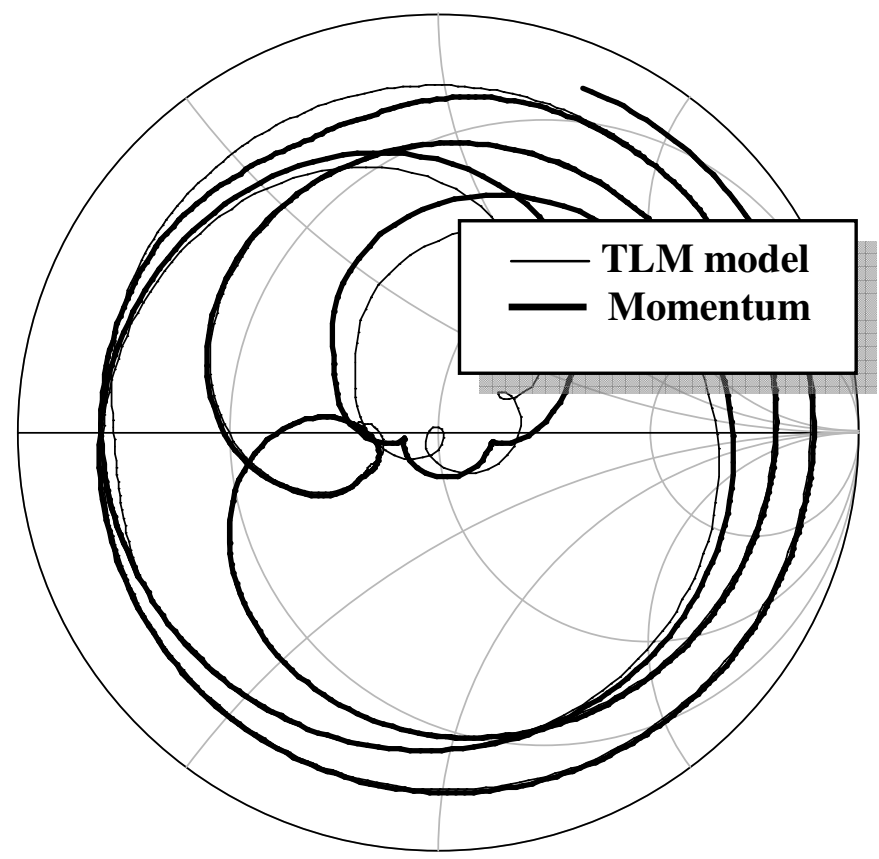

Figure 8. Smith's chart of the input impedance return losses. Frequency points given by start $=6.0 \mathrm{GHz}$, stop $=14.0 \mathrm{GHz}$.

The input impedance or the antenna has been calculated over a frequency range of 6.0-14.0 GHz. It can be seen from Figure 8 that the comparison for the input impedance between transmission line model and the moment method results are in good agreement. One notices that the resonant frequency is very close to the axis of $50 \mathrm{Ohm}$.

\subsection{Bi-band Bow-tie antennas array operating at the frequencies 4.3 and $16 \mathrm{GHz}$}

In this part, a second antenna array is designed to operate at a frequency of $4.3 \mathrm{GHz}$ and 16 GHz. The antennas array characteristics are: $\mathrm{W}_{1}=8 \mathrm{~mm}, \mathrm{~W}_{2}=1.5 \mathrm{~mm}, \mathrm{~L}=36.86 \mathrm{~mm}, \varepsilon_{\mathrm{r}}=4.6$, $\mathrm{h}=0444 \mathrm{~mm}, \operatorname{tg} \delta=0.0018$ and thickness of metallization $\mathrm{T}=0.05 \mathrm{~mm}$. A probe of $50 \Omega$ is used to feed the antennas array through a quarter-wave line to en sure a perfect match. The geometry of this array is shown in figure 9 .

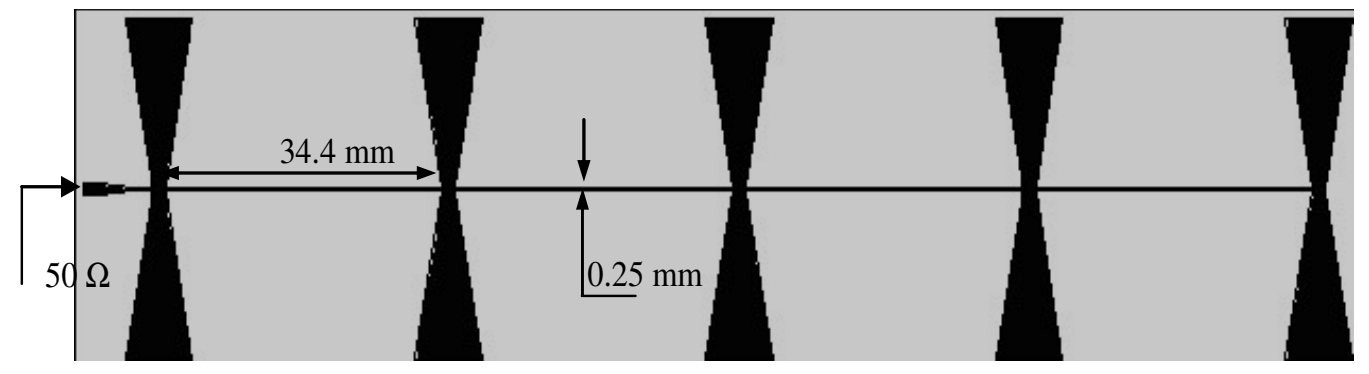

Figure 9. The mask layout of the bi-band bow-tie antennas array design operating at 4.3 and $16.0 \mathrm{GHz}$ 
International Journal of Computer Networks \& Communications (IJCNC) Vol.4, No.4, July 2012

The simulated input return loss of the bi-band bow-tie antennas array is displayed for frequencies between 2.0 to $18.0 \mathrm{GHz}$ in figure 10 .

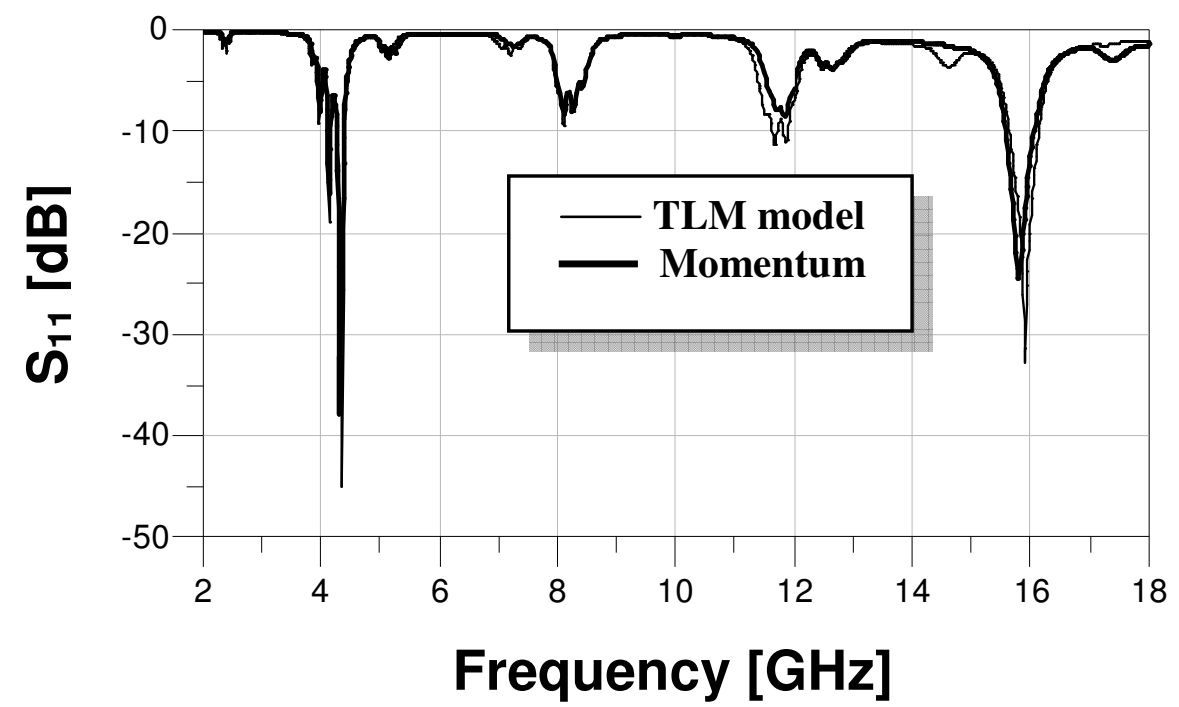

Figure 10. computed return loss of the bi-band bow-tie antennas array

According to the result obtained on the figure 10, we notice that there is a perfect match between the two models with an excellent matching, the two resonance frequencies are correctly determined and the curves are indistinguishable.

The simulated antenna input VSWR is displayed for frequencies between 2.0 to $18.0 \mathrm{GHz}$ in figure 11.

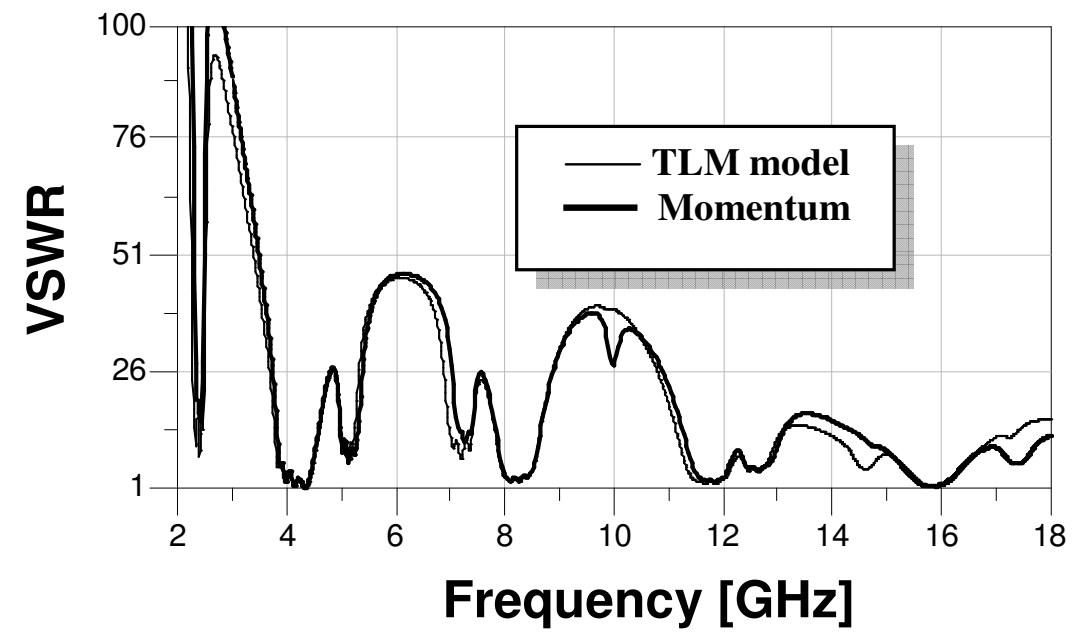

Figure 11. simulated input VSWR of the bi-band bow-tie antennas array 
International Journal of Computer Networks \& Communications (IJCNC) Vol.4, No.4, July 2012

According to the result shown in figure 11, we see an excellent agreement between the two models (the transmission line model and the moment's method). The VSWR level at resonant frequencies is near unity, which implies an ideal adaptation of the antenna.

The simulation result on the reflected phase at the antenna input is shown in figure 12.

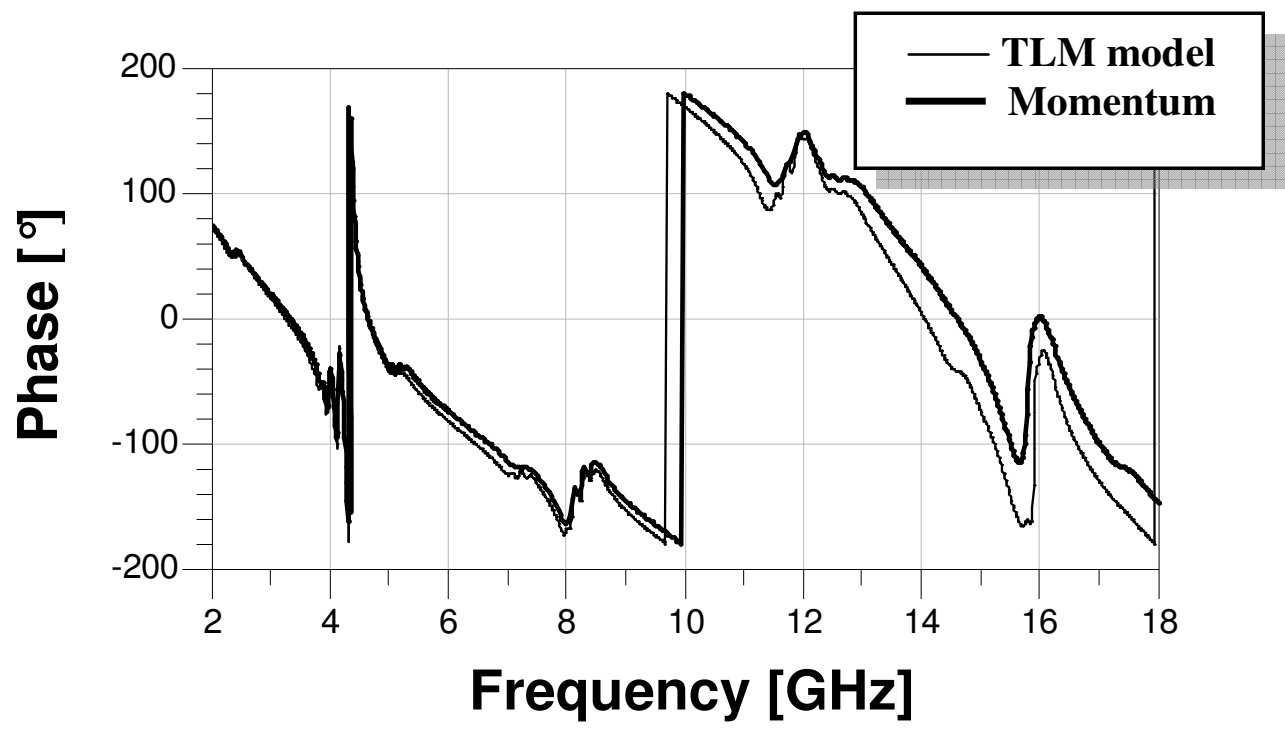

Figure 12. computed reflected phase of bi-band bow-tie antennas array

One notices very well that the phase is null by the two models at the two resonant frequencies in spite of the shift observed. The impedance locus of the antennas array over a frequency range of 2.0- $18.0 \mathrm{GHz}$ is illustrated on Smith's chart in figure 13.

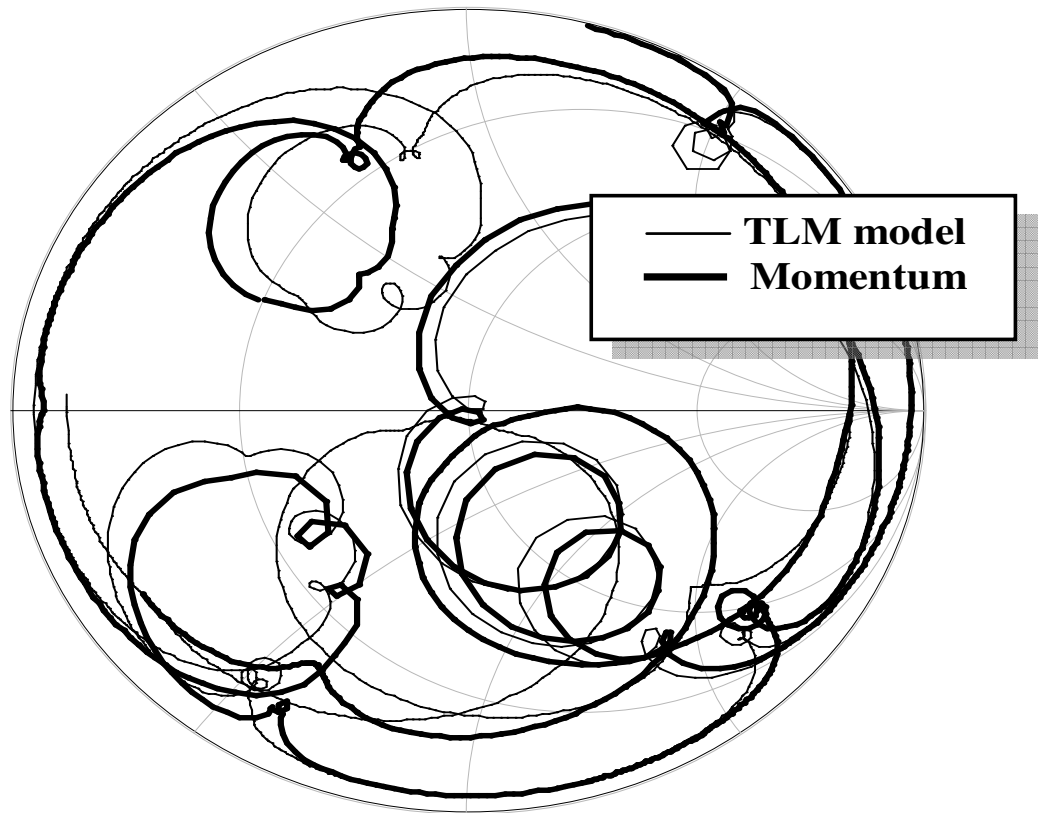

Figure 13. Smith's chart of the input impedance return losses. Frequency points given by start $=2.0 \mathrm{GHz}$, stop $=18.0 \mathrm{GHz}$. 
International Journal of Computer Networks \& Communications (IJCNC) Vol.4, No.4, July 2012

It can be seen from figure 13 that the comparison for the input impedance between transmission line model and the moment method results are in good agreement. One notices that the resonant frequency is very close to the axis of $50 \mathrm{Ohm}$.

\section{CONCLuSiON}

In this paper we presented the simulation results of bi-band bow-tie antennas array design fed in series by microstrip line using an equivalent simple transmission line model. Two bi-band antennas arrays were simulated operating at different resonant frequencies. The first array operates at 8.6 and $12.6 \mathrm{GHz}$ frequency and a second dual-band array operates respectively at a frequency 4.3 and $16 \mathrm{GHz}$. The simulations results obtained by the transmission line model were compared with those obtained by a rigorous method which is the moment's method of the momentum software. Based on this study, an original model for the bow-tie antennas array fed in series by microstrip line has been established. Excellent results were obtained by comparing the proposed model and the method of moments for the various simulated antennas arrays.

\section{REFERENCES}

[1] Abri M, Boukli-hacene N, Bendimerad FT, Cambiaggio E. Design of a Dual Band Ring Printed Antennas Array. Microwave journal 2006; 49(5):228-232.

[2] Ribero JM, Staraj R, Damiano JP. Analytical models for fast analysis and synthesis of various printed Antennas. Antennas and associated systems for mobil satellite communication 1997. P. 508515 .

[3] Abri M, Boukli-hacene N, Bendimerad FT. Ring printed antennas arrays radiation. Application to multibeam. Mediterranean Microwave Symposium, Marseille, 2004.

[4] Hui HT, Chan KY, Yung EKN. A Low Profile Hemispherical Helical Antenna with Circular Polarization Radiation over a Wide Angular Range. IEEE trans on ant and prop; 2003; 51(7):14151418.

[5] Sang-Hyuk W, Jung-Min K, Jong-Gwan Y. Microstrip-Fed Bow-Tie-Shaped Meander Slot Antenna With Compact And Broadband Characteristics. Microwave and optical technology letters 2005; 45(1):88-90.

[6] Abdelnasser AE, Atef ZE, Charles ES. Wideband Microstrip-Fed Printed Bow-Tie Antenna For Phased array systems. Microwave and optical technology letters 2004; 43(2): 123-126

[7] Shih-Yuan C, Powen H. A Modified Bow-Tie Slot Antenna Fed By A Coplanar Waveguide. Antennas and Propagation Society International Symposium, 2004. p. 799-802.

[8] Balanis CA. Antenna Theory Analysis and Design, Second Edition: John Wiley and Sons, 1997.

[9] James JR, Hall PS, Handbook of Microstrip antennas: Peter Peregrims, London, UK, 1989.

[10] Derneryd AG. A Theoretical Investigation of the Rectangular Microstrip Antenna. IEEE trans AP 1978; 26(4):532-535.

[11] Derneryd AG. Linearly Polarized Microstrip Antennas. IEEE trans AP 1976; 846-851.

[12] Pues H, Van de chapelle A. Accurate Transmission Line Model for the Rectangular Microstrip Antenna. IEE Microwave Antennas and propagation; 1984, 131(6):334-340.

[13] Bhartia P, Rao KVS, Tomar RS. Millimeter-wave Microstrip and Printed Antennas. Norwood: Artech House, 1991.

[14] Bahl IJ, Bhartia P, Microstrip Antennas, Norwood: Artech House Dedham, 1980.

[15] Hammerstad EO. Equations of Microstrip Circuit Design, Proc. Fifth European Microwave conf, 1975. p. 268-272. 